\title{
Trabalhador-consumidor: a atração de jovens pelo employer branding na escolha profissional
}

\author{
ANdRea POleto Oltramari ${ }^{1}$ \\ ROSANA CÓRDOVA ${ }^{2}$ \\ MARIA JOSÉ TONELLI ${ }^{3}$ \\ 1 UNIVERSIDAdE FEDERAL do RIO GRANDE do SUL (UFRGS) / \\ Programa de Pós-Graduação em Administração, Porto Alegre - RS, Brasil \\ ${ }^{2}$ Universidade Federal do RIO GRANDE do SUl (UFRGS) / EsCola de AdMINISTRAÇÃO, PORTO AlEGRE - RS, BRASIL \\ ${ }^{3}$ FundaçÃo Getulio VARgas (FGV EAESP) / Escola de AdministraçÃo de EMPRESAS de SÃo Paulo, \\ Departamento de Administração Geral e Recursos humanos, SÃo PaUlo - SP, Brasil
}

\section{Resumo}

O objetivo neste artigo discutir criticamente a importância da marca para a escolha profissional de jovens estudantes de graduação que prospectam vagas em empresas. A pesquisa A pesquisa se baseia no aparato conceitual contemporâneo de employer branding, consumo e estilo de vida, prosumption e cocriação. Os procedimentos de coleta de dados incluíram entrevistas semiestruturadas com dezoito estudantes ao final do curso de Administração de uma Universidade Federal no sul do país. Os principais resultados apontam que os jovens tornam-se prosumidores das marcas empregadoras; que a carreira amparada pela busca da melhor marca mostra-se como uma empreitada e está associada a trabalhos intermitentes, o que torna as relações de trabalho cada vez mais vulneráveis. Mas, apesar de o jovem trabalhador escolher a marca empregadora, esta parece não ter atrativos suficientes para retê-lo numa carreira a longo prazo.

Palavras-chave: Trabalho. Consumo. Employer branding.

\section{Young people's career choices based on employer branding}

\section{Abstract}

This article critically discusses the relevance of brands in young undergraduate students' choices when looking for internships and jobs. The research is based on the debate around the modern concepts of employer branding, consumption and lifestyle, and prosumption and co-creation. Interviews were conducted with 18 students at the end of an undergraduate program in business administration at a public university in the south of Brazil. The main results show that younger students become prosumers of their employer's brands and their careers are based on seeking to work for the best brands, which is associated to intermittent jobs and vulnerable work relationships. However, the employers do not seem to offer enough elements to retain young workers.

Keywords: Labor. Consumption. Employer branding.

\section{Trabajador-consumidor: la atracción de jóvenes por el employer branding en la elección profesional}

\section{Resumen}

El objetivo de este artículo es realizar una discusión crítica sobre la importancia de la marca para la elección profesional de jóvenes estudiantes de graduación, que prospectan vacantes en empresas. La investigación se apoya en el debate conceptual contemporáneo sobre el employer branding, el consumo y el estilo de vida, prosumo y cocreación. Los procedimientos de recolección de datos incluyeron entrevistas semiestructuradas y observaciones sistemáticas con 18 estudiantes al final del curso de Administración de una universidad federal del sur del país. Los principales resultados apuntan que: los jóvenes se vuelven prosumidores de las marcas empleadoras; la carrera, amparada por la búsqueda de la mejor marca, se muestra como una empresa y está asociada a trabajos intermitentes, lo que hace que las relaciones de trabajo sean cada vez más vulnerables. Pero, a pesar de que la elección del joven trabajador se apoye en la marca empleadora, esta parece no tener los atractivos suficientes para retenerlo para una carrera a largo plazo.

Palabras clave: Trabajo. Consumo. Employer branding. 


\section{INTRODUÇÃO}

Estudos que articulam trabalho e consumo vêm sendo realizados por uma série de autores que tratam do prosumption ou cocriação (CÓRDOVA, 2016; FONTENELLE, 2014, 2015a, 2015b; PRAHALAD e RAMASWAMY, 2004a, 2004b; TOFFLER, 1980), do consumidor como produtor de valor (CHERKOVSKAYA e LOAKER, 2016; DALE, 2012; FONTENELLE, 2015a), em especial por meio da internet (RITZER, 2014); da economia ética (ARVIDSSON, 2010; ARVIDSSON e PEITERSEN, 2013); do trabalho imaterial (GORZ, 2003; LAZZARATO e NEGRI, 2001) e do trabalho voluntário (PEARCE, 1993) ou free labor (ANDREJEVIC, 2013; HESMONDHALGH, 2013; TERRANOVA, 2003). Se, por um lado, existem autores que apontam inúmeros aspectos positivos dos novos formatos de trabalho, nos quais o consumidor é trazido para o centro da criação de valor a partir dos processos de cocriação (BOTSMAN e ROGERS, 2011; PRAHALAD e RAMASWAMY, 2004b), por outro, existem perspectivas críticas que indicam a exploração ainda mais intensa do trabalhador a partir do prosumption (COMOR, 2010a, 2010b; FONTENELLE, 2014; GORZ, 2003; LAZZARATO e NEGRI, 2001, 2015a). Nessa perspectiva que trata da relação entre trabalho e consumo também se inserem as discussões sobre employer branding (EB). Utilizamos neste artigo a tradução aproximada para "marca empregadora", conceito de empresa que gerencia sua marca para que ela sustente a imagem relacionada a uma boa empresa para se trabalhar (AMBLER e BARROW, 1996; BACKHAUS e TIKOO, 2004; CHERTKOVSKAYA, WATT, TRAMER et al., 2013; DALE, 2012; DELL e AINSPAN, 2001; LAND e TAYLOR, 2010). Ela também tem por objetivo atrair candidatos, especialmente despertando o desejo deles tanto de construir carreira na empresa, quanto de ter em seus currículos passagens por empresas que propagam uma boa imagem no mercado. Assim, não é necessario ser empregado da empresa para existir uma relação de employer branding. $O$ candidato com frequência desenvolve um relacionamento socialmente cooperativo com as empresas marcas empregadoras, especialmente pelo fato de propagar boas referências sobre sua marca em sua ampla rede de contatos. Além de trabalhar na empresa, o empregado se identifica com sua marca e a consome. Uma marca pode ser entendida como um nome, um sinal, um símbolo ou como um conjunto de ambos que serve para identificar e distinguir a oferta de uma organização daquela de seus concorrentes (CHURCHILL e PETER, 2003; LOURO, 2000).

Embora escassos, os estudos brasileiros sobre o tema tratam dessa relação entre empregados e marcas de modo positivo (OLTRAMARI, TONELLI e COSTA, 2015; REIS e BRAGA, 2016;). Nosso objetivo neste artigo é discutir criticamente a importância da incorporação da marca por estudantes de graduação que prospectam vagas para construir a carreira. Busca-se compreender como o sentido de prosumer foi incorporado por esses jovens na procura por trabalho. Desse modo, primeiramente apresentamos os conceitos básicos deste trabalho: employer branding, cocriação e prosumption; em seguida, apresentamos os procedimentos metodológicos de coleta, análise e discussão de dados e por fim, as considerações finais.

\section{CONCEITOS}

\section{Employer branding}

Ambler e Barrow (1996) definiram employer branding a partir de um estudo exploratório realizado em empresas no Reino Unido sobre a importância da aplicação de técnicas de gerenciamento da marca na gestão de recursos humanos. A conclusão do estudo é que o conceito de employer branding é algo potencialmente valioso para as organizações, e que fazer uso de técnicas de gerenciamento de marcas na gestão de recursos humanos adiciona valor ao patrimônio corporativo de acordo com a perspectiva do consumidor. Para os autores, a definição de employer branding seria "[...] o pacote de benefícios funcionais, econômicos e psicológicos providos pelo emprego e que se identificam com a empresa empregadora" (AMBLER e BARROW, 1996, p. 187). É importante acrescentar que o employer branding também se relaciona com a construção de uma imagem nas mentes dos potenciais trabalhadores de que aquele espaço é um ótimo local para se trabalhar (BERTHON, EWING e HAH, 2005).

O levantamento sobre o tema realizado por Aggerholm, Andersen e Thomsen (2011) mostra uma literatura que inclui: 1) uma noção estática de employer branding em que as proposições da marca empregadora são definidas pelos estrategistas de marca com base na identidade desta; 2) a exposição e transmissão das proposições do employer branding internamente (o branding interno auxilia a organização a alinhar a cultura corporativa com interesses da marca) e externamente (a partir do entendimento de que a propaganda deve atingir todos os stakeholders e não somente o consumidor final); 3) práticas lineares de employer branding que se detêm somente na atratividade do empregador e na produtividade do empregado; 4) um canal para realçar experiências do consumidor, de um olhar integrado sobre o gerenciamento de marca, que permite influenciar a lealdade do consumidor e a perfo. 
Para Aggerholm, Andersen e Thomsen (2011), os estudos relacionados com employer branding adotam uma noção desatualizada de gerenciamento da marca, que está enraizada em ideais funcionalistas da relação entre empregadores e empregados, e falham ao não apresentar os desafios organizacionais e as pressões societais. Assim, abre-se uma brecha para pensar, por exemplo, a relação com a cocriação de valor, na medida em que se percebe uma mudança do locus de produção econômica de valor para o locus de cocriação de valor (PRAHALAD e RAMASWAMY, 2004a, 2004b).

Em estudos recentes sobre EB e recursos humanos, há artigos que versam sobre gestão de recursos humanos sustentáveis (APP, MERK e BUTTGEN, 2012), dimensões de atratividade (BERTHON, EWING e HAH, 2005; CHHABRA e SHARMA, 2014; WILDEN, GUDERGAN e LINGS, 2010) e recursos humanos e mídias sociais (SIVERTZEN, NILSEN e OLAFSEN, 2013).

As pesquisas sobre o tema employer branding realizadas no Brasil, na área de administração, versam sobre a atração e o desligamento de jovens da geração $Y$ por marcas empregadoras, atrelando o estudo à cultura organizacional da empresa (OLIVEIRA e HONÓRIO, 2014), estratégias de recrutamento, seleção e retenção de pessoas (OLTRAMARI, TONELLI e COSTA, 2015) e políticas de retenção de jovens (REIS e BRAGA, 2016). Os estudos sobre o tema são escassos e por se tratar de um tema muito recente, há muito o que se pesquisar sobre o conceito de employer branding, cocriação e prosumption. Além disso, muitos trabalhos que tratam do tema são conceituais, com raras apresentações de dados empíricos. Nesse sentido, esta pesquisa traz dados de entrevistas sobre como esses conceitos foram incorporados pelos jovens na busca por trabalho. Porém, para adentrar na discussão de cocriação e prosumption, é necessário refletir a respeito da busca por um estilo de vida que está cada vez mais associado ao consumo.

A sociedade de consumo está associada a um estilo de vida que tem na busca incessante de felicidade seu principal motor (BAUMAN, 2007, 2008). A vida associada ao consumo é analisada por Baudrillard (2005), que a remete também aos templos de consumo, aos shopping centers, a "pirâmides de objetos a desabar" (BAUDRILLARD, 2005, p. 16). Tal estilo de vida invade a existência por completo e também impregna as relações sociais. As catedrais de consumo são associadas a imagens e informações que devem ter obsolescência acelerada (BAUDRILLARD, 2005), ao desperdício (LIPOVETSKY, 1989), à liberação e ao incentivo de um rápido crescimento das despesas individuais. O consumidor age obedecendo a um código, em especial o código do pensamento compartilhado pelo coletivo, que é aderido ao excesso do consumo, ou à abundância (BAUDRILLARD, 2005). Nessa linha, quem não for adepto do consumo voraz acaba por não pertencer ao coletivo. O reconhecimento social também diz respeito à sociedade de consumo contemporânea e o fato de ele não acontecer pode, na sociedade líquidomoderna, evocar tensão contínua.

O consumo ganha outra dimensão ainda não suficientemente explorada (FONTENELLE, 2014) numa relação de trabalho ou de emprego. Exemplificando, trabalho e consumo se confundem tornando-se impossível separar tempo de trabalho e tempo de não trabalho (LAZZARATO e NEGRI, 2001). O trabalho passa a ser também consumo no capitalismo imaterial (FONTENELLE, 2014), sendo, portanto, a "plenitude do trabalho abstrato" (OLIVEIRA, 2003). A internet, por exemplo, potencializa esse fenômeno, passando claramente a incluir as possibilidades de coparticipação do consumidor nos processos de criação de empresas de novos produtos (ARVIDSSON, 2005, 2006, 2008). Assim, consumidor e consumo contemporâneo não podem ser compreendidos separadamente do mundo do trabalho e da produção (CÓRDOVA, 2016; FONTENELLE, 2015b).

Há uma aceleração do consumo garantindo sua venda antes mesmo da produção (ABíLIO, 2011) e uma garantia que o trabalhador (ao assumir a responsabilidade do serviço e da venda do produto para si mesmo) veja-se como capital (porque, além de consumir o produto, ele o cria), e não mais somente como força de trabalho.

Desse modo, as empresas têm usado a estratégia de marca empregadora para atrair e reter os melhores candidatos, e assegurar que os futuros empregados estejam engajados com a cultura e com a estratégia da empresa (REIS e BRAGA, 2016). A marca empregadora investe na sua imagem mostrando para todos que é um lugar destacado e excelente para se trabalhar. Essa estratégia pode se dar porque acreditam que esses mesmos candidatos e trabalhadores têm um grande potencial de difundir a marca da empresa como consumidores e fazer dela o desejo de consumo de muitas pessoas. Há características do prosumer no movimento dos candidatos em direção a uma vaga de trabalho em marcas empregadoras, como: o trabalho não remunerado sendo realizado pelo candidato (TERRANOVA, 2003); o consumo como investimento e direcionado ao trabalho (FONTENELLE, 2015a, 2015b); o investimento da relação social e o envolvimento emocional com a marca e com o produto como um prenúncio da confiança a ser estabelecida (ARVIDSSON, 2005). Os prosumers trabalham primordialmente sem compensação financeira (RITZER, DEAN e JURGENSON, 2012). A sociedade de consumo na contemporaneidade está em busca da transitoriedade e da busca por confiança, conceito que será discutido na próxima seção. 


\section{Cocriação e prosumption: nas raízes do consumo}

Há uma série de artigos, em especial a partir do ano 2000, que aponta que não podemos mais somente olhar para a produção sem considerar o consumidor (ver GABRIEL e LANG, 2008; RITZER, GOODMAN e WIEDENHOFT, 2001). Entretanto, é na Terceira Onda (TOFFLER, 1980) que se observou pela primeira vez que as fronteiras entre produção e consumo se apresentam borradas, ou seja, não é possível pensar uma esfera descolada da outra.

O termo prosumption, por exemplo, já se referia ao processo de embaralhamento das fronteiras que separavam o produtor do consumidor nos anos 1980 (GABRIEL e LANG, 2008). Na atualidade esse termo ganhou força e passou a ser cada vez mais associado e integrado à produção do valor para o capitalismo (ARVIDSSON, 2008; FONTENELLE, 2015b). Esse termo é essencialmente "[...] saudado como uma forma de empoderamento do consumidor. A partir de uma vertente crítica, autores apontam uma nova forma de alienação e exploração do trabalho" (FONTENELLE, 2015b, p. 84).

A alienação e a exploração do trabalho podem se dar como a extensão do trabalho para a esfera do consumo (OLIVEIRA, 2003). Exemplificando, na esfera do trabalho passa-se a incluir uma ampla gama de processos de cocriação, coprodução e coparticipação do consumidor. É o "do-it-yourself" ou "faça você mesmo", proposto por Toffler (1980).

O prosumer é aquele que interage com ferramentas como Youtube, Wikipedia; Facebook, Booking, Amazon, etc. Em alguns casos, ele é protagonista na criação e gerenciamento do conteúdo; em outros, ele realiza avaliações sobre hotéis, livros e serviços em geral. Além da criação do produto e de serviço, tem-se também os self-checkouts e self-check-ins como uma experiência de compartilhamento individual e coletivo da marca (RITZER, 2014).

Nessa lógica, o sujeito passa a ser também "gestor de si" (LÓPEZ-RUIZ, 2007), termo derivado dos estudos sobre o trabalho imaterial (LAZZARATO e NEGRI, 2001). O trabalho imaterial, para os autores, configura uma nova relação produção-consumo na qual a demanda do trabalho recai sobre a capacidade intelectual e afetiva dos trabalhadores, resultando em uma maior captura da vida pessoal e profissional.

A sobreposição do tempo produtivo com o tempo de lazer pode ser também observada da ótica do sharing economy e dos processos de cocriação. Há uma literatura (ver AIGRAIN e AIGRAIN, 2012; BOTSMAN e ROGERS, 2011; PRAHALAD e RAMASWAMY, 2004b; TAPSCOTT e WILLIAMS, 2010) que faz uso dos termos sharing economy, consumo colaborativo e cocriação sem, necessariamente, atrelá-los a uma perspectiva crítica, segundo a qual se analisam aspectos relacionados às novas formas de exploração e precariedade do trabalho (GILL e PRATT, 2008), por exemplo.

No entanto, existem autores existem autores que tratam criticamente o tema da cocriação: Zwick, Bonsu e Darmody (2008, p. 168) mostram como pessoas da área de marketing “[...] tipicamente consideram ter relacionamentos com consumidores como algo que as empresas deveriam aspirar, pois boas relações se traduzem em lucros mais altos". Por meio de uma desconstrução sobre a invenção das "relações com o consumidor" no pensamento do marketing, Zwick, Bonsu e Darmody (2008) se afastam do conceito de cocriação de Prahalad e Ramaswamy (2004b) para encontrar diálogos que conceituam a cocriação da lógica geral de produção nas economias informacionais capitalistas (HESMONDHALGH, 2010; TERRANOVA, 2003) e nas teorizações críticas sobre valor da marca (ARVIDSSON, 2006).

De acordo com Zwick, Bonsu e Darmody (2008, p. 182), a "[...] noção de cocriação representa uma tecnologia sofisticada de governar os consumidores onde a mais-valia gerada é baseada na apropriação frequente do trabalho criativo em rede e socialmente cooperativo dos consumidores". Ainda assim, tendo esse conceito como base e sabendo da sua importância, isso ainda se constitui como uma fronteira não totalmente ultrapassada, ainda que se busque reiteradamente um maior controle sobre os mercados (ZWICK, BONSU e DARMODY, 2008). O conceito de prosumer, o produtor-consumidor, ou como estamos utilizando neste artigo, o conceito de trabalhador-consumidor, está subsumido nas novas formas de organização do trabalho e nas novas formas de recrutamento e seleção. Acabamos de indicar que a separação entre sujeito-trabalho-empresa-consumo não é mais tão nítida. Os conceitos de trabalhador e consumidor se mesclam e as empresas usam o consumo das marcas para fidelizar também os trabalhadores, atraídos por seus valores e significados sociais.

Mas, embora o conceito de trabalhador-consumidor seja debatido tanto na prática das empresas como em estudos acadêmicos, poucos estudos empíricos buscam mostrar como se dá a incorporação da marca pelos trabalhadores, especialmente por aqueles que iniciam suas carreiras. Em contribuição ao debate, a pesquisa empírica apresentada na próxima seção traz alguns insights sobre a relação da marca empregadora com a escolha profissional de jovens que estão concluindo o curso de Administração. 


\section{PROCEDIMENTOS METODOLÓGICOS}

O presente estudo privilegia uma abordagem qualitativa da questão apresentada, servindo-se de entrevistas semiestruturadas e observações sistemáticas, o que resulta numa interpretação mais profunda das relações que se estabelecem entre as categorias de análise (FLICK, 2004; SYMON e CASSEL, 2012; TRIVIÑOS, 1987). A escolha do método traduz também uma visão epistemológica com consequências práticas para a escolha do objeto a ser estudado, e a abordagem teórica adotada dá a forma da coleta e analisa os dados (SYMON e CASSEL, 2012). Para responder ao objetivo da pesquisa, ou seja, compreender como se constrói o employer branding para estudantes ao final de um curso de administração de uma universidade federal do sul do país, foram entrevistados 18 jovens entre 21 a 25 anos, 5 mulheres e 13 homens respectivamente. A seleção dos entrevistados foi feita por acessibilidade e por indicação e disponibilidade dos próprios entrevistados.

O roteiro da entrevista contou com as seguintes questões, sempre associadas a marca empregadora: conhecimento sobre as marcas; razão da procura por candidatura; vantagens e desvantagens em trabalhar em uma empresa com marca empregadora; razão em construir carreira; o que espera encontrar em uma empresa considerada de marca empregadora; o que empresas com marca empregadora têm que outras empresas não têm, e vice-versa; apontar o nome de uma marca empregadora (a primeira que vem à mente). Apresentamos no Quadro 1 uma síntese dos dados dos entrevistados. Note-se que todos os jovens entrevistados eram alunos ao final do curso de graduação, mas que, em paralelo, exerciam atividades de estágio ou eram funcionários em diferentes tipos de empresas.

Tal como são as pesquisas qualitativas, deparou-se com um universo de significados, tanto no momento da coleta dos dados como no momento posterior de análise. A estruturação das categorias se deu a posteriori, pela utilização da análise de conteúdo (MINAYO, 2001). O conteúdo das falas, gravado e transcrito, foi debatido coletivamente entre as autoras, de modo a buscar os significados presentes nos dados; e sistematizado, seguindo os preceitos de exaustividade, homogeneidade e pertinência (BARDIN, 2016).

\section{Quadro 1}

Características dos entrevistados

\begin{tabular}{|c|c|c|l|}
\hline Entrevistados & Sexo & Idade & \multicolumn{1}{|c|}{ Função ocupada na época da entrevista } \\
\hline E1 & M & 22 & Estagiário \\
\hline E2 & M & 21 & Estagiário em empresa pública \\
\hline E3 & M & 23 & Bancário \\
\hline E4 & F & 23 & Analista em Empresa varejista \\
\hline E5 & M & 23 & Empreendedor \\
\hline E6 & M & 21 & Auxiliar em Empresa familiar \\
\hline E7 & M & 22 & Trabalho voluntário na AlESEC \\
\hline E8 & M & 21 & Estagiário empresa de pequeno porte \\
\hline E9 & M & 21 & Funcionário de uma startup \\
\hline E10 & M & 23 & No momento da entrevista, sem estágio e/ou atividades profissionais \\
\hline E11 & F & 23 & Estagiária empresa pública \\
\hline E12 & M & 21 & Voluntário da Empresa júnior \\
\hline E13 & F & 23 & Estagiária pequena empresa \\
\hline E14 & M & 24 & Estagiário em uma multinacional no Panamá \\
\hline E15 & F & 24 & Bancária \\
\hline E16 & F & 23 & Funcionária empresa setor telecomunicações \\
\hline E17 & F & 25 & Estagiária participando de processos seletivos \\
\hline E18 & F & 22 & Funcionária empresa setor cosméticos \\
\hline
\end{tabular}

Fonte: Elaborado pelas autoras. 
Seguindo os princípios de exaustividade, homogeneidade e permanência (BARDIN, 2016), o conteúdo das falas foi classificado e posteriormente analisado. Para Moraes (2007), a análise de conteúdo é um processo de desconstrução dos textos em que surgem unidades de análise e estas unidades são identificadas com base em um sentido pertinente ao propósito da pesquisa. Assim, estabelecemos como núcleos de sentidos das falas: 1) A marca empregadora e 2) O estagiário prosumidor: o produtor/ consumidor da empresa marca empregadora.

\section{Descrição, análise e discussão dos resultados}

Iniciamos destacando das falas dos entrevistados os principais pontos relativos à importância da marca e, na sequência, a discussão sobre a marca empregadora e o estagiário prosumidor.

Os estudantes indicam que a marca empregadora tem uma utilidade prática, já que "agrega ao curriculum" (E1), mas também revelam "empresas mais saudáveis" (E3), pois estas se mantêm há mais tempo no mercado. No entanto, esses estudantes também relevam que os valores das empresas e seus propósitos precisam estar alinhados com os seus próprios valores (E5). O quadro 2 apresenta, sinteticamente, a importância da marca para cada um dos entrevistados e suas trajetórias.

\section{Quadro 2}

\section{A importância da marca empregadora}

\begin{tabular}{|c|c|c|c|c|c|}
\hline Alunos/Sexo & Semestre & Sexo & Importância da Marca & Idade & Trajetórias dos estudantes \\
\hline E1 & 9 & M & $\begin{array}{l}\text { "Trabalhar em uma marca empregadora } \\
\text { agrega bastante no currículo, mas não é só } \\
\text { isso o que im porta. Bem-estar para mim é } \\
\text { importante". }\end{array}$ & 22 & $\begin{array}{l}\text { Estagiou em vários lugares por pouco } \\
\text { tempo. No momento está focando na } \\
\text { formatura e está se preparando para fazer } \\
\text { processo seletivo em uma empresa de } \\
\text { marca empregadora. }\end{array}$ \\
\hline E2 & 9 & M & $\begin{array}{l}\text { Acredita que a marca empregadora dá mais } \\
\text { empregabilidade, ser reconhecido pelo } \\
\text { currículo pela passagem em uma empresa } \\
\text { com marca. }\end{array}$ & 21 & Estagiou em órgão público. \\
\hline E3 & 10 & M & $\begin{array}{l}\text { Acredita que empresas de marca empregadora } \\
\text { (ME) são mais saudáveis, no sentido de que } \\
\text { conseguem sobreviver mais facilmente } \\
\text { às crises por já estarem estabilizadas no } \\
\text { mercado. Acredita também que, apesar de } \\
\text { ser importante o bem-estar, a reputação de } \\
\text { trabalhar num lugar com uma marca forte } \\
\text { abre portas. No entanto, preza muito a relação } \\
\text { da estabilidade. }\end{array}$ & 23 & $\begin{array}{l}\text { Estagiou primeiramente em um banco, } \\
\text { após isso trabalhou numa das maiores } \\
\text { empresas do RS. }\end{array}$ \\
\hline E4 & 10 & $\mathrm{~F}$ & $\begin{array}{l}\text { Trabalhar em uma ME agrega muito no } \\
\text { currículo, mas para ela é importante ter } \\
\text { essa experiência. Acredita que os valores } \\
\text { da marca têm de ser alinhados com os seus. }\end{array}$ & 23 & $\begin{array}{l}\text { Estagiou em uma empresa varejista de } \\
\text { marca empregadora. Atualmente está se } \\
\text { preparando para a formatura. }\end{array}$ \\
\hline E5 & 8 & M & $\begin{array}{l}\text { Acredita que, com certeza, uma empresa de } \\
\text { ME chama atenção no currículo. Mas tem } \\
\text { que se ter propósito e se sentir bem quando } \\
\text { se trabalha. }\end{array}$ & 23 & $\begin{array}{l}\text { Ele estagiou em uma empresa de porte } \\
\text { médio e atualmente procura empreender. }\end{array}$ \\
\hline E6 & 8 & M & $\begin{array}{l}\text { Acredita que uma empresa com nome é } \\
\text { sim super-reconhecida. Ele relata que foi } \\
\text { doutrinado pela familia a procurar empresas } \\
\text { multinacionais, pois terá grande retorno } \\
\text { profissional e financeiro. Acredita que as } \\
\text { pessoas levam em consideração a reputação } \\
\text { de trabalhar em uma marca. Mas acredita } \\
\text { também que tem que ter qualidade de vida } \\
\text { no trabalho. }\end{array}$ & 22 & $\begin{array}{l}\text { Estagiou em várias empresas de porte } \\
\text { pequeno e familiar. }\end{array}$ \\
\hline
\end{tabular}


continuação

\begin{tabular}{|c|c|c|c|c|c|}
\hline Alunos/Sexo & Semestre & Sexo & Importância da Marca & Idade & Trajetórias dos estudantes \\
\hline E7 & 8 & M & $\begin{array}{l}\text { Ele optou por trabalhar na AIESEC, pois teria } \\
\text { um crescimento em gestão muito maior do } \\
\text { que em qualquer outra empresa. Mas, com } \\
\text { certeza, quando for trabalhar em uma empresa, } \\
\text { verificará muito bem antes se os valores dela } \\
\text { condizem com seus valores pessoais. }\end{array}$ & 22 & $\begin{array}{l}\text { Estagiou no setor financeiro de um escritório } \\
\text { de advocacia. Logo após decidiu se dedicar } \\
\text { a AIESEC, trabalhando volunariamente. }\end{array}$ \\
\hline E8 & 9 & M & $\begin{array}{l}\text { Acredita que se não tivesse trabalhado em } \\
\text { uma marca empregadora não estaria bem } \\
\text { estabilizado agora. "Quem passa nessas } \\
\text { empresas se destacou no processo seletivo } \\
\text { e isso é bem visto." } \\
\text { Mas é importante para ele que a empresa seja } \\
\text { transparente e trabalhar por um propósito. }\end{array}$ & 21 & $\begin{array}{l}\text { Estagiou primeiramente em um banco, } \\
\text { logo depois numa marca empregadora } \\
\text { e decidiu sair, pois, não era reconhecido } \\
\text { por ela. Optou por uma empresa de porte } \\
\text { menor onde poderia se desenvolver } \\
\text { mais profissionalmente. Em meio a } \\
\text { isso, participava da AIESEC e do Centro } \\
\text { Acadêmico. }\end{array}$ \\
\hline E9 & 8 & M & $\begin{array}{l}\text { Trabalhar em uma marca empregadora é } \\
\text { uma estratégia curricular. No entanto, não } \\
\text { haverá uma marca que se alinhe com todos } \\
\text { os seus valores. }\end{array}$ & 21 & $\begin{array}{l}\text { Estagiou primeiramente em um banco não } \\
\text { tão conhecido. Posteriormente foi para } \\
\text { outro de alta reputação, ao mesmo tempo } \\
\text { que trabalhava voluntariamente no Centro } \\
\text { Acadêmico. Logo após foi convidado para } \\
\text { trabalhar numa startup, aceitou, pois se } \\
\text { alinhava com seu propósito de vida. }\end{array}$ \\
\hline E10 & 9 & M & $\begin{array}{l}\text { Acredita que trabalhar em uma ME é uma } \\
\text { ótima experiência, porque te mostra uma } \\
\text { visão multinacional. Mas tem que gostar } \\
\text { também de estar lá. }\end{array}$ & 23 & $\begin{array}{l}\text { No momento está se envolvendo mais } \\
\text { com a área acadêmica. Posteriormente } \\
\text { vai procurar empreender. }\end{array}$ \\
\hline E11 & 8 & $\mathrm{~F}$ & $\begin{array}{l}\text { “A gente sabe que inegavelmente para muitos } \\
\text { ter uma grande empresa no currículo pesa, mas } \\
\text { também há a questão da competência, muitas } \\
\text { vezes tu acaba sendo 'esvaziado'. Como até um } \\
\text { professor uma vez ligou - 'tens que escolher } \\
\text { se tu queres estar no rabo do tubarão ou na } \\
\text { cabeça da sardinha'. Na empresa pequena, tu } \\
\text { está fazendo de tudo e às vezes pode propiciar } \\
\text { um crescimento muito maior do que em uma } \\
\text { empresa grande, mas também tem a opção de } \\
\text { estabilidade e de um desenvolvimento. Tem } \\
\text { empresa que tem programa de capacitação } \\
\text { nos estágios muito bom. Às vezes tem um } \\
\text { programa de desenvolvimento no estágio } \\
\text { muito bom. É preciso pesquisar muito uma } \\
\text { ME antes de tentar entrar, para ver se aquilo } \\
\text { que dizem condiz com a realidade". }\end{array}$ & 23 & $\begin{array}{l}\text { Estagiou em órgão público e em uma } \\
\text { autarquia. }\end{array}$ \\
\hline E12 & 10 & M & $\begin{array}{l}\text { Acredita que ME é um peso no currículo. No } \\
\text { entanto, tem que ser um ambiente agradável. } \\
\text { Ele pesa mais o ambiente de trabalho do } \\
\text { que nome da empresa ou dinheiro/salário... }\end{array}$ & 21 & $\begin{array}{l}\text { Participa da empresa júnior. Interpretou } \\
\text { que teria muito mais desafios lá dentro. }\end{array}$ \\
\hline E13 & 9 & $\mathrm{~F}$ & $\begin{array}{l}\text { Acredita que estagiar em uma empresa } \\
\text { grande e multinacional amplia seu ponto } \\
\text { de vista. Relata que, com certeza, faz muita } \\
\text { diferença no currículo para a sociedade e } \\
\text { caso queira concorrer a uma vaga em uma } \\
\text { empresa cobiçada. }\end{array}$ & 23 & $\begin{array}{l}\text { Seu primeiro estagio foi em uma empresa } \\
\text { pequena. Depois passou em um processo } \\
\text { seletivo para participar de uma das maiores } \\
\text { empresas do RS. No entanto, após um } \\
\text { tempo, voltou para seu antigo estágio por } \\
\text { questões de propósito e de valores. }\end{array}$ \\
\hline E14 & 10 & M & $\begin{array}{l}\text { Acredita ser muito importante ter no currículo } \\
\text { uma empresa de } \mathrm{ME} \text {, pelo fato de dar a pessoa } \\
\text { uma noção do mundo que nenhuma empresa } \\
\text { de porte pequeno poderia dar. }\end{array}$ & 24 & $\begin{array}{l}\text { Seu único estágio foi em uma marca } \\
\text { empregadora e lá foi efetivado. Agora foi } \\
\text { transferido pela mesma empresa para o } \\
\text { Panamá. }\end{array}$ \\
\hline
\end{tabular}




\begin{tabular}{|c|c|c|c|c|c|}
\hline Alunos/ Sexo & Semestre & Sexo & \multicolumn{1}{|c|}{ Importância da Marca } & Idade & Trajetórias dos estudantes \\
\hline E15 & 10 & F & $\begin{array}{l}\text { Estratégia de currículo, mas também porque } \\
\text { a remuneracão era uma das melhores } \\
\text { trabalhando 6 horas diárias. Mas acredita } \\
\text { que tem que se sentir bem onde trabalha. }\end{array}$ & 24 & $\begin{array}{l}\text { Seu primeiro estágio foi em um banco } \\
\text { grande, no entanto não se sentiu reco- } \\
\text { nhecida e atualmente está trabalhando } \\
\text { em outra empresa menor, mas que está se } \\
\text { desenvolvendo profissionalmente. }\end{array}$ \\
\hline E16 & 10 & F & $\begin{array}{l}\text { Gostaria de trabalhar em uma empresa com } \\
\text { marca empregadora porque acredita que } \\
\text { a remuneração é maior e as condições de } \\
\text { trabalho são melhores. }\end{array}$ & 23 & $\begin{array}{l}\text { Atualmente trabalha como analista do setor } \\
\text { de telecomunicações, mas estuda para } \\
\text { passar em um concurso público. }\end{array}$ \\
\hline E17 & 10 & F & $\begin{array}{l}\text { Acredita que ter trabalhado em marca } \\
\text { empregadora agrega muito no currículo. }\end{array}$ & 25 & $\begin{array}{l}\text { Estagiária de uma empresa e está partici- } \\
\text { pando de vários processos seletivos. }\end{array}$ \\
\hline E18 & 9 & F & $\begin{array}{l}\text { Quer trabalhar em marcas empregadoras em } \\
\text { vários países do mundo. }\end{array}$ & 22 & Funcionária do setor de cosméticos. \\
\hline
\end{tabular}

Fonte: Elaborado pelas autoras.

Da análise das entrevistas emergiram dois temas principais: a marca empregadora e o estagiário prosumidor, que apresentamos respectivamente.

\section{A marca empregadora}

Há um desejo muito forte no relato dos jovens (E1, E3, E4, E5, E6, E8, E10, E11, E16 e E17) em ingressar em uma empresa com marca empregadora. Tal desejo é apontado por alguns autores (OLTRAMARI, TONELLI e COSTA, 2015) como a destacada imagem organizacional, alicerçada pelas suas estratégias que em especial reverberam nas políticas de gestão de pessoas, em especial na remuneração, carreira e qualidade de vida no trabalho) em harmonia, e de acordo com o que Legge (2005) intitula de estratégias hard de gestão de pessoas.

Esse desejo é observado no relato dos jovens para ingressar em uma empresa com marca empregadora, destacada na sua imagem organizacional. No entanto, chama a atenção que eles não relataram o desejo de permanecer nas empresas, mas, de, especialmente, ter em seus currículos a passagem por uma marca empregadora (foram relatados os desejos de trabalhar em empresas como Google, Dell, Netflix, McDonald's). Não conseguem visualizar seu futuro profissional por mais de cinco anos na mesma empresa, tal como revela a fala de E7, com a qual corroboram, em linha, especialmente E1, E3, E5, E9, E10, E12 e E17.

Eu não consigo me ver criando uma carreira numa empresa por cinco anos. O trabalho fica repetitivo e isso desmotiva. E também o produto da empresa vai ser sempre o mesmo. Vai chegar um ponto que vou cansar daquele lugar. Para mim, eu quero rodar em outras empresas grandes. Esse seria meu plano de carreira (E7).

Ainda, segundo um dos entrevistados:

Acho que ficar dois anos em uma empresa marca empregadora deve fazer diferença no currículo. Seis meses é pouco. Aí a gente sai e procura outra empresa se perceber que a marca empregadora não está oferecendo o que gostaríamos (E1).

Segundo os entrevistados, o tempo médio de permanência em uma empresa gira em torno de três anos, o que eles consideram muito longo. A efemeridade das relações e a aceleração do tempo são protagonistas nessa nova relação que se estabelece entre o trabalhador e a organização (BAUDRILLARD, 2005; BAUMAN, 2007, 2008). Em uma sociedade em que as relações são efêmeras, tal como Bauman (2007) e Lipovestky (2007a) já anunciavam, a prontidão, ou seja, mudar repentinamente de táticas e estilo, abandonar compromissos e lealdades e buscar oportunidades mais de acordo com sua disponibilidade atual do que com as próprias preferências tornam-se a regra da vez.

Um dos pontos enfatizados pelos entrevistados é a questão do trânsito, da passagem por várias empresas, o que vai ao encontro das considerações de Baumam (2007) acerca da importância da velocidade em detrimento da durabilidade. Afora isso, o tédio pode produzir uma sensação de comodidade, característica que não é bem vista aos olhos não somente desses jovens como dos 
empregadores. Além disso, a necessidade de status pode ser preenchida a partir do momento que fazem parte do quadro de funcionários da empresa. Sem conhecer como as políticas e práticas de recursos humanos são estruturadas, os entrevistados acreditam que as marcas empregadoras têm maior orçamento para investimento em pessoas e consequentemente podem investir mais em qualificação e carreira internacional, afora as políticas de recrutamento e seleção serem mais sofisticadas, prioritariamente pelas redes sociais, conforme relatos. Exemplificando, um dos entrevistados (E2) diz: "[...] acredito que a marca empregadora nos dê mais empregabilidade, sermos reconhecidos em nosso currículo pela passagem em uma empresa com marca". Se antes, a área de recursos humanos seduzia o trabalhador pelas suas políticas (KEENOY, 1999; TOWNLEY, 2002), na atualidade elas começam a seduzi-lo antes mesmo do seu ingresso na organização, em especial porque a marca passa a ter um valor importante para ele. Assim, a marca apresenta-se como organizadora dos processos e das práticas de recursos humanos, pela sua posição protagonista e influente na contratação de trabalhadores.

Durante as entrevistas, pareceu também que jovens que se candidatam a uma vaga na empresa não sabem ao certo no que irão trabalhar, não sabem até mesmo o que de fato a empresa vende, o que E3 corrobora: "Quando eu entrei na empresa, foi por querer ter uma experiência em uma marca forte. Só que pensava que ela era só o produto X e estando lá percebi que essas empresas são muito mais do que é visto no dia-a-dia. Tem vários outros produtos que passam despercebidos".

Os jovens desejam que as políticas de recursos humanos existam e sejam fortes, tal como exemplifica um deles: "[...] marcas empregadoras têm mais carreira, plano de saúde, benefícios, jornada de trabalho flexível, canal de comunicação aberta" (E4). Embora argumentem que pouco desfrutaram de tais políticas, mencionam que elas atraem muito e que isso também diz respeito à manutenção de uma boa marca empregadora: "isso ajuda na reputação da marca" e " a marca tem propósito e a ideia de excelência". A marca apresenta-se como uma alavanca, um recurso que permite perpetuar e manter um status "elitizado". Esse acesso inicia quando ingressam no curso de graduação, que pode ser considerado como "selo" de acesso às marcas empregadoras. O selo de acesso não parece valer para universidades em termos gerais, mas corrobora os estudos de Rocha-de-Oliveira, Piccinini e Bittencourt (2012), segundo os quais a inserção profissional não se apresenta de forma homogênea para as juventudes no mercado de trabalho.

Os entrevistados afirmaram que estão dispostos até mesmo a obter uma remuneração menor, se assim for necessário, para ingressar em uma empresa com marca empregadora. Falam da sensação de bem-estar em trabalhar em empresas que segundo eles "são estáveis" (E7), o que aqui contrasta com a efemeridade, apresentando uma contradição entre a estabilidade que buscam e a urgência e pressa na construção da carreira. O consumo do emprego pode representar o que López-Ruiz (2007) afirma sobre o consumo ser investimento, ou seja, essas empresas recebem uma ordem valorativa na sociedade e acabam, pela marca empregadora, sendo objeto de consumo e investimento por parte dos candidatos. Ainda, segundo Ritzer, Dean e Jurgenson (2012), os produtores/consumidores trabalham muitas vezes sem a compensação financeira, sendo motivados mais pelo status e pertencimento à marca do que pelo próprio salário.

Após um ou dois anos, se não forem promovidos ou tiverem uma ascensão rápida, muitos têm a ideia de buscar um novo desafio profissional, demonstrando pouca paciência para aguardar e construir a carreira. O formato de contrato tradicional, com promessas de segurança e longo prazo, deu espaço para um novo tipo de contrato, o de curto prazo, renovado com base nas necessidades atuais e na performance do trabalhador. Acredita-se que os jovens buscam novos desafios, tanto porque não têm paciência com o formato de trabalho, quanto porque a precariedade de suas relações os empurra para isso. Para Bauman (2008, p. 46), que denomina esse tipo de momento como a cultura apressada, "[...] o tempo na sociedade líquida-moderna de consumidores não é cíclico nem linear, como costumava ser para os membros de outras sociedades [...] ele é marcado por rupturas e descontinuidades, por intervalos que separam pontos sucessivos e rompem os vínculos entre eles". Para Bauman (2008) um ambiente líquido-moderno é inóspito ao planejamento, investimento e armazenamento em longo prazo.

Os alunos gostam da mudança e da mobilidade; não se veem construindo carreira em um mesmo lugar, em especial porque há uma necessidade constante de se nutrirem de novidades, tal como Bauman (2008) diz da necessidade de substituir objetos "ultrapassados" na perspectiva da sociedade líquido-moderna. Em especial, a carreira em marcas empregadoras adquire um status de promessa de muitos benefícios em relação à vida profissional. Interessante notar na fala dos entrevistados certo alívio quando o assunto é mobilidade, ligado à crença de que, se estão se movendo, não estão em comodidade, como eles intitulam. As empresas também têm em suas políticas o incentivo dessa conduta relacionada ao consumo do emprego e à velocidade da carreira. A política da vida, assim como a natureza das relações interpessoais, tende a ser remodelada à semelhança dos meios e objetos de consumo e segundo as linhas sugeridas pela síndrome consumista (BAUMAN, 2007). A carreira, assim, tornou-se um meio para ter mobilidade e consumir o emprego. Percebe-se, portanto, que tais jovens estão 
sempre mirando no futuro e não no presente, usando a carreira como um trampolim para algo que imaginam ser mais alto, de mais status, mas absolutamente intangível, porque é incerto, ao passo que antes era um meio para conseguir remuneração para realizar desejos de compras pessoais. Ou seja, tange o desejo em algo concreto.

As suas carreiras estão se construindo cada vez mais tendo-os como gestores de si tal como a literatura já vem apresentando (OLTRAMARI, 2015; OLTRAMARI e GRISCI, 2014). Há uma primazia da marca na vida dos estudantes, o que atesta o comportamento de "caçadores de marcas" na busca por trabalho. A marca, sobretudo, autoriza a ascensão na carreira e faz os alunos trabalharem pelo futuro, não pelo presente - a marca é, sobretudo, um capital para o futuro.

Os entrevistados foram também questionados a respeito das vantagens e desvantagens em relação a construir carreira em marcas empregadoras. $\mathrm{O}$ fato do candidato ter trabalhado em uma marca empregadora eleva a chance de concorrer a uma vaga no mercado de trabalho. Segundo um dos alunos entrevistados e que trabalha na área de gestão de pessoas de uma empresa: "[...] quando tem algum candidato que fez pelo menos cinco anos em uma empresa marca empregadora vejo com bons olhos, acho que o candidato traz um bom currículo por ter passado por marcas empregadoras" (E20). Evidenciam-se, aqui, mais uma vez, as contradições que aparecem e que alimentam as escolhas e a construção da carreira dos jovens. No próximo tópico serão discutido o prosumidor e a marca empregadora e a relação entre eles.

\section{O estagiário prosumidor: o produtor-consumidor da empresa com marca empregadora}

Há um envolvimento, uma possível conexão entre employer branding, o desejo de consumir a marca com a perspectiva do prosumer (FONTENELLE, 2014, 2015b; RITZER, DEAN e JURGENSON, 2012), ou seja, o desejo de consumo da empresa com marca empregadora passa pelo produção-consumo do trabalhador que extrapola o horário contratual da sua jornada e da sua remuneração. $O$ elemento-chave deste conceito - prosumer - é que o trabalhador não necessariamente enxerga esse fato como algo ruim, mas como algo que acrescenta ao seu currículo, que o atualiza e o faz permanecer no circuito de ofertas de emprego das marcas empregadoras. É o que vemos na fala de E11 quando afirma que, por trabalhar em um banco, deveria usar o cartão deste mesmo banco.

De alguma forma, os gerenciadores das marcas compreenderam que os consumidores têm um papel importante - diríamos que fundamental - na produção de significados compartilhados do que é a marca (RITZER, DEAN e JURGENSON, 2012). Os jovens alunos são prosumidores que produzem significados que circundam marcas empregadoras como Google, Coca-Cola e Facebook. Existe "[...] uma relação social, um significado compartilhado, um envolvimento emocional que não estava lá antes" (ARVIDSSON, 2005, p. 237). Tal informação é percebida na conversa com E10, quando afirma que possui total liberdade para "ajudar a marca" e enxerga isto como algo positivo. Esse envolvimento emocional do prosumidor também pode ser encontrado no relato de E7, que usa deliberadamente sua própria rede social para compartilhar promoções e "retuítar" informações da empresa em que trabalha; e também na fala de E8, segundo o qual experimenta sapatos da loja na qual trabalha e, em seguida, posta na rede social Instagram. Nenhuma dessas atividades é vista como trabalho pelos entrevistados.

Sobre esse aspecto do trabalho versus não trabalho, Arvidsson (2006) argumenta que não é mais possível indicar uma diferença fenomenológica entre trabalho produtivo e consumo improdutivo, ou seja, há uma dimensão produtiva do consumo (LAZZARATO e NEGRI, 2001). Quando um entrevistado (E7) afirma que deixou de beber Coca-Cola porque está estagiando na Ambev, e outro (E16) que, ao estagiar em uma empresa de elevadores, começou a andar de elevador em todos os locais onde ia fora do horário de expediente, evidencia-se essa não diferenciação. É como se os consumidores fossem convidados a completar os produtos, seja materialmente, seja simbolicamente (ARVIDSSON, 2006). É nessa interatividade programada (que as empresas com marca empregadora estão constantemente atentas) que reside o núcleo principal do brand management contemporâneo (ARVIDSSON, 2005, 2006).

Um dos conceitos-chave para a compreensão do que é ser considerada uma (boa) marca empregadora está no esforço que setores de atração e retenção de talentos fazem para a permanência do funcionário, ou para que o estagiário evolua para uma carreira efetiva. Por isso a preocupação com a identificação do candidato em relação à marca empregadora. Por meio dessa mútua identificação e, levando-se em conta que estamos falando de estagiários prosumidores, torna-se possível, como diria Arvidsson (2006, p. 35), "[...] colocar a atenção e os outros afetos dos consumidores para trabalhar". 
Assim, por um lado, temos empresas com marca empregadora com um discurso para "atrair talentos", que propiciam experiências e capacitam os jovens para a produção e cocriação dispondo de seus afetos; por outro lado, temos jovens que procuram uma marca reconhecida no mercado para trabalhar e dar início às suas carreiras.

É importante citar que o consumo também diz respeito ao trabalho voluntário (TERRANOVA, 2003). No momento em que os entrevistados referem-se às atividades associadas ao trabalho voluntário, que, por sua vez, os auxiliam na estratégia de inserção nas empresas com marca empregadora, seu tempo de lazer está sendo consumido pelo trabalho, assumindo assim a característica do trabalho imaterial, no qual todo o tempo de vida é invadido pelo trabalho. $O$ trabalho voluntário apresenta-se não como altruísmo, mas como investimento na carreira e, assim, é cada vez maior o investimento no trabalho imaterial (TERRANOVA, 2003). Há um desejo de seguir investindo no tempo de não trabalho, na lógica do trabalho imaterial, principalmente para estudar formas estratégicas de construir a carreira, tal como relata um entrevistado (E6): “[...] estudo fora do horário de trabalho sobre futebol americano porque sei que essa informação vai agregar valor tanto para a empresa quanto para meu currículo". Na lógica do free labor, se oferece e se recebe informação sem a mediação do pagamento em dinheiro (TERRANOVA, 2003). Para Terranova (2003), ainda, faz parte do free labor encorajar os trabalhadores a entrar em contato com as mudanças do mundo no que tange ao conhecimento e à informação, sendo essa atividade sempre exercida no momento de não trabalho ou de lazer.

Somos todo o tempo convidados a contribuir para algo, o que, segundo Terranova (2003), significa dizer que somos explorados descaradamente no cotidiano do trabalho e, sobretudo, no cotidiano da vida. Se retomarmos a ideia de cocriação segundo Prahalad e Ramaswamy (2004a, 2004b), sempre foi uma preocupação das empresas conseguir acessar competências e habilidades especializadas dos consumidores. Para Zwick, Bonsu e Darmody (2008), além de atrair e reter os consumidores, as empresas estão preocupadas em providenciar um ambiente criativo e de comunicação livre, onde os consumidores (entendidos também como trabalhadores) possam aplicar e melhorar seus conhecimentos para que "todos" se beneficiem. São esses espaços característicos da era pós fordista que tornam possível a inteligência humana renovar sua capacidade de produzir, nos quais o trabalhador-consumidor representa a mais pervasiva e mais produtiva forma de trabalho, dada a exploração da força de trabalho (ver LAZZARATO e NEGRI, 2001).

\section{CONSIDERAÇÕES FINAIS}

Se em López-Ruiz (2009) vemos que o executivo busca atualizar seus conhecimentos para continuar a fazer parte da organização, na pesquisa realizada vemos um esforço dos jovens para pertencer de uma maneira distinta, não pela atualização dos estudos - já que ainda são estudantes de graduação - mas por meio da relação com a marca, o que se expressa em suas postagens, retuítes, comentários em redes sociais, etc. Nosso estudo mostra que o estilo de vida dos jovens vem afetando a relação com a marca empregadora, a qual quer se empoderar do estilo de vida dos jovens com a intenção de que eles se tornem cada vez mais prosumidores. No entanto, as políticas de gestão de pessoas, tal como estão, não são suficientes para manter esses jovens nas organizações.

Afora isso, é possível inferir que a carreira tem se mostrado cada vez mais como empreitada, associada a trabalhos intermitentes e tornando as relações de trabalho cada vez mais vulneráveis. Dos estudos que dizem da carreira como "eu sociedade anônima" ou "do gestor de si", agora a cooptação e sedução do trabalhador se dá pela marca. Mesmo que, importante salientar, por um breve momento.

As marcas empregadoras, com suas políticas de gestão de pessoas, não conseguem manter os jovens por longos prazos. Mesmo investindo na marca (seja compartilhando conteúdos das empresas nas redes sociais, caracterizando o trabalho para além do horário contratual), eles não querem permanecer na empresa. Vemos aqui o hedonismo da juventude caracterizado por relações efêmeras, seja com pessoas ou com organizações. A reputação e a construção do currículo se amparam no nome dessas marcas. O jovem incorpora o discurso da marca empregadora, mesmo que para isso ele tenha que investir em trabalho voluntário, o que toma completamemte o tempo da sua vida.

Observa-se uma dimensão afetiva presente na relação entre os estagiários e as empresas com marca empregadora, no sentido de que elas buscam colocar os afetos dos estagiários prosumidores 'para trabalhar', mediadas em grande parte pelas novas tecnologias (redes sociais, internet). Por isso é tão importante a identificação e posterior retenção do estagiário prosumidor, 
pois a empresa poderá dispor, de maneira deliberada, dos afetos que são desenvolvidos entre ela e o funcionário e que resultam na divulgação dela como um bom local para se trabalhar, algo que pode fortalecer seu brand management.

Estudos acerca da mudança de perfil dos profissionais ao longo do tempo já haviam previsto outras competências para os trabalhadores, e projetado que, na atualidade, seria quase impossível permanecer 10 a 20 anos na mesma empresa. Acredita-se que tal mudança diga tanto do desejo dos jovens quanto da instabilidade que se apresenta nas relações laborais brasileiras.

Em relação às políticas de gestão de pessoas, os jovens se referem à sedução exercida estrategicamente por estar políticas. Também percebemos que a marca empregadora se vê obrigada a trabalhar melhor suas políticas de atração e retenção porque ela não está somente dando atenção a jovens alunos, mas prosumidores, cocriadores que interagem de maneira distinta com ela.

Para concluir, consideramos que o número de entrevistados é uma limitação do estudo. Excetuando isso, salienta-se que é um estudo regional que considerou somente uma universidade federal e, especificamente, de um estado no sul do Brasil. Para futuros estudos sugerimos dar sequência ao diálogo entre políticas de gestão de pessoas, novos estilos de vida e consumo. Como aspecto positivo, cabe ressaltar novamente que trouxemos uma aproximação do prosumer com o employer branding. Além disso, acredita-se que vale pesquisar o quanto a instabilidade nessas relações estariam ancoradas nas relações laborais brasileiras. 


\section{REFERÊNCIAS}

ABÍLIO, L. C. O Make Up do Trabalho: uma empresa e um milhão de revendedoras de cosméticos. 2011. 307 p. Tese (Doutorado em Ciências Sociais) - Universidade Estadual de Campinas, Instituto de Filosofia e Ciências Humanas, Camopinas, 2011.

AGGERHOLM, H. K.; ANDERSEN, S. E.; THOMSEN, C. Conceptualizing employer branding in sustainable organizations. Corporate Communications: An International Journal, v. 16, n. 2, p. 105-123, 2011.

AIGRAIN, P.; AIGRAIN, S. Sharing: culture and the economy in the internet age. Amsterdam: Amsterdam University Press, 2012.

AMBLER, T.; BARROW, S. The employer brand. Journal of Brand Management, v. 4, n. 3, p. 185-206, 1996.

ANDREJEVIC, M. Estranged Free Labor. In: SCHOLZ, T. (Ed.). Digital Labor: the internet as playground and factory. New York: Routledge, 2013. p. 149-164.

APP, S.; MERK, J.; BUTTGEN, M. Employer Branding: Sustainable HRM as a Competitive Advantage in the Market for High - Quality Employees. Management Revue, v. 23, n. 3, p. 262-278, 2012.

ARVIDSSON, A. Brands: a critical perspective. Journal of Consumer Culture, v. 5 n. 2, p. 235-258, 2005.

ARVIDSSON, A. Brands: meaning and value in media culture. London: Routledge, 2006.

ARVIDSSON, A.; PEITERSEN, N. The Ethical Economy: Rebuilding Value after the Crisis. New York: Columbia University Press, 2013.

ARVIDSSON, A. The ethical economy of customer coproduction. Journal of Macromarketing, v. 28, n. 4, p. 326-338, 2008.

ARVIDSSON, A. The ethical economy: new forms of value in the information society. Organization. v.17, n. 5, p. 637-644, 2010.

BACKHAUS, K; TIKOO, S. Conceptualizing and researching employer branding. Carreer Development International, v. 9, n. 5, p. 501517, 2004.

BARDIN, L. Análise de Conteúdo. São Paulo: Edições, 2016.

BAUDRILLARD, J. A Sociedade de Consumo. Lisboa: Edições 70, 2005.

BAUMAN, Z. Vida líquida. Rio de Janeiro: Jorge Zahar, 2007.

BAUMAN, Z. Medo líquido. Rio de Janeiro: Jorge Zahar, 2008.

BERTHON, P.; EWING, M.; HAH, L. L. Captivating company: dimensions of attractiveness in employer branding. International Journal of Advertising: The Review of Marketing Communications, v. 24, n. 2, p. 151-172, 2005.

BOTSMAN, R.; ROGERS, R. What's mine is yours: how collaborative consumption is changing the way we live. London: Collins, 2011.

CHERTKOVSKAYA, E. et al. Giving notice to employability. Ephemera: theory \& politics in organization, v. 13, n. 4, p. 701-716, 2013.

CHHABRA, N. L.; SHARMA, S. Employer branding: strategy for improving employer attractiveness. International Journal of Organizational Analysis, v. 22, n. 1, p. 4-60, 2014.

CHURCHILL, G. A; PETER, J. P. Marketing: criando valor para os clientes. São Paulo: Saraiva, 2003.
COMOR, E. Contextualizing and Critiquing the Fantastic Prosumer: Power, Alienation and Hegemony. Critical Sociology, v. 37, n. 3, p. 309-327, 2010a.

COMOR, E. Digital prosumption and alienation. Ephemera: theory \& politics in organization, v. 10, n. 3-4, p. 439-454, 2010b.

CÓRDOVA, R. G. Interfaces entre trabalho e consumo: uma proposta de discussão acerca das definições sobre o processo de cocriação. In: ENCONTRO NACIONAL DOS ESTUDOS DO CONSUMO (ENEC), 8., 2016, Niterói. Anais... Niterói: ENEC, 2016.

DALE, K. The employee as 'dish of the day': The ethics of the consuming/ consumed self in human resources management. Journal of Business Ethics, v. 111, n. 1, p. 13-24, 2012.

DELL, D. J.; AINSPAN, N. Engaging employees through your brand. In: THE CONFERENCE BOARD OF CANADA, 2001, Ottawa. Proceedings... New York: Conference Board, 2011.

FLICK, U. Uma introdução à pesquisa qualitativa. Porto Alegre: Bookman, 2004.

FONTENELLE, I. A. O Estatuto do Consumo na Compreensão da Logística e das Mutações do Capitalismo. Lua Nova: Revista de Cultura e Política, São Paulo, v. I, n. 92, p. 207-240, 2014.

FONTENELLE, I. A. Organizations as producers of consumers. Organization, London, v. 22, n. 5, p. 644-660, 2015a.

FONTENELLE, I. A. Prosumption: As Novas Articulações entre Trabalho e Consumo na Reorganização do Capital. Revista Ciências Sociais Unisinos, v. 51, n. 1, p. 83-91, 2015b.

FONTENELLE, I. A. O Fetiche do Eu Autônomo: Consumo Responsável, Excesso e Redenção como Mercadoria. Psicologia \& Sociedade, v. 22, p. 215-224, 2010.

FONTENELLE, I. A. Global Responsibility through Consumption? Resistance and assimilation in the anti-brand movement. Critical perspectives on international Business, v. 6, p. 256-272, 2010.

GABRIEL, Y.; LANG, T. The Unmanageable Consumer: Contemporary Consumption and its fragmentations. London: Sage Publications, 2008.

GILL, R.; PRATT, A. Precarity and Cultural Work in the Social Factory? Immaterial Labour, Precariousness and Cultural Work. Theory, Culture \& Society, v. 25, n. 7-8, p. 1-30, 2008.

GORZ, A. Metamorfoses do trabalho: crítica da razão econômica. São Paulo: Annablume, 2003.

HESMONDHALGH, D. User-generated content, free labour and cultural industries. Ephemera: theory \& politics in organization, v. 10, n. 3-4, p. 267-284, 2010.

KEENOY, T. HRM as hologram: A polemic. Journal of Management Studies, v. 41, n. 3, p. 1-23, 1999.

LAND, C.; TAYLOR, S. Surf's Up: Work, balance and brand in a new age capitalist organization. Sociology (British Sociological Association), v. 44, n. 3, p. 395-413, 2010.

LAZZARATO, M.; NEGRI, A. Trabalho Imaterial: formas de vida e produção de subjetividade. Rio de Janeiro: DP\&A, 2001. 
LEGGE, K. Human Resource Management: Rhetorics and Realities (Anniversary ed.). Basingstoke: Palgrave MacMillan, 2005.

LIPOVETSKY, G. O império do efêmero: a moda e seu destino nas sociedades modernas. São Paulo: Companhia das Letras, 1989.

LÓPEZ-RUIZ, O. Os executivos das transnacionais e o espírito do capitalismo: Capital humano e empreendedorismo como valores sociais. São Paulo: Azougue Editorial, 2007.

LOURO, M. J. S. Modelos de Avaliação de Marca. Revista de Administração de Empresas, v. 40, n. 2, p. 26-37, 2000.

MINAYO, M. C. S. (Org.). Pesquisa social: teoria, método e criatividade. Petrópolis: Vozes, 2001.

MORAES, R. Análise textual discursiva. Porto Alegre: Unijuí, 2007.

OLIVEIRA, F. O ornitorrinco. São Paulo: Boitempo, 2003.

OLIVEIRA, L, B.; HONÓRIO, S. R. F. S. Atração e desligamento voluntário de jovens empregados: um estudo de caso no setor jornalístico. Revista de Administração - RAUSP, v. 49, n. 4, p. 714-730, 2014.

OLTRAMARI, A.; GRISCI, C. L. Carreira e família na sociedade líquidomoderna. Revista de Administração Mackenzie, v. 15, n. 1, p. 15-48, 2014.

OLTRAMARI, A.; TONELLI, M. J.; COSTA, A. C. Employer Branding: Análise Das Estratégias Narrativas de Marcas Empregadoras para Atração e Retenção de Trabalhadores. In: ENCONTRO DE GESTÃO DE PESSOAS E RELAÇÕES DE TRABALHO, 5., 2015, Salvador. Anais... Salvador: EnGPR, 2015.

OLTRAMARI, A. Transição na carreira e quantofrenia: um estudo de caso com coordenadores de mestrado e doutorado de uma IES privada. Revista de Carreira e Pessoas, v. 5, n. 2, p. 200-210, 2015.

PEARCE, J. L. Volunteers: The organizational behavior of unpaid workers. London: Routledge, 1993.

PRAHALAD, C. K.; RAMASWAMY, V. Co-creation experiences: the next practice in value creation. Journal of Interactive Marketing, v. 18, n. 3 , p. $5-14,2004 a$.

PRAHALAD, C. K.; RAMASWAMY, V. The future of competition: co-creating unique value with customers. Boston: Harvard University Press, 2004b.
REIS, G. G.; BRAGA, B. M. Employer attractiveness from a generational perspective: Implications for employer branding. Revista de Administração, v. 51, n. 1, p. 103-116, 2016.

RITZER, G.; DEAN, P.; JURGENSON, N. The Coming of Age of the Prosumer. American Behavioral Scientist, v. 56, n. 4, p. 379398, 2012.

RITZER, G.; GOODMAN, D.; WIEDENHOFT, W. Theories of consumption. In: RITZER, G.; SMART, B. (Eds.). Handbook of Social Theory. London: Sage, 2001. p. 410-427.

RITZER, G. Prosumption, evolution, revolution, or eternal return of the same? Journal of Consumer Culture, v. 14, n. 1, p. 3-24, 2014.

ROCHA-DE-OLIVEIRA, S. R.; PICCININI, V. C.; BITENCOURT, B. M. Juventudes, gerações e trabalho: é possível falar em geração $Y$ no Brasil? Organizações \& Sociedade, v. 19, n. 62, p. 551-558, 2012.

SIVERTZEN, A.; NILSEN, R.; OLAFSEN, A. H. Employer branding: employer attractiveness and the use of social media. Journal of Product \& Brand Management, v. 22, n. 7, p. 473-483, 2013.

SYMON, G.; CASSEL, C. Qualitative organizational research: core methods and current challenges. London: Sage, 2012.

TASPCOTT, D.; WILLIAMS, A. D. Wikinomics: how mass collaboration changes everything. New York: Portfolio, 2010.

TERRANOVA, T. Free Labor: producing culture for the digital economy. 2003. Disponível em:<http://www.electronicbookreview.com/thread/ technocapitalism/voluntary>. Acesso em: 12 dez. 2016.

TOFFLER, A. A terceira onda. Rio de Janeiro: Record, 1980.

TOWNLEY, B. Managing with modernity. Organization, v. 9, n. 4, p. $549-573,2002$.

TRIVIÑOS, A. N. B. Introdução à pesquisa em ciências sociais: A pesquisa qualitativa em educação. São Paulo: Atlas, 1987.

WILDEN, R.; GUDERGAN, S.; LINGS, I. Employer branding: strategic implications for staff recruitment. Journal of Marketing Management, v. 26, n. 1-2, p. 56-73, 2010.

ZWICK, D.; BONSU, S. K.; DARMODY, A. Putting consumers to work: Co-creation and new marketing govern-mentality. Journal of Consumer Culture, v. 8, n. 2, p. 163-196, 2008. 
Andrea Poleto Oltramari

ORCID: https://orcid.org/0000-0002-5897-2772

Doutora em Administração pela Universidade Federal do Rio Grande do Sul (UFRGS); Professora Adjunta na Universidade Federal do Rio Grande do Sul (UFRGS), Porto Alegre-RS, Brasil. E-mail: andrea.oltramari@ufrgs.br

\section{Rosana Córdova}

ORCID: https://orcid.org/0000-0002-5120-1385

Doutora em Administração na Escola de Administração de Empresas de São Paulo da Fundação Getulio Vargas (FGV EAESP); Professora Adjunta na Universidade Federal do Rio Grande do Sul (UFRGS), Porto Alegre-RS, Brasil. E-mail: rosana.cordova@ufrgs.br

Maria José Tonelli

ORCID: https://orcid.org/0000-0002-6585-1493

Professora Titular no Departamento de Administração Geral e Recursos Humanos na Escola de Administração de Empresas de São Paulo da Fundação Getulio Vargas (FGV EAESP), São Paulo - SP, Brasil. E-mail: maria.jose.tonelli@fgv.br 